SAND 98-0505/12

\title{
ENTNEA:
}

A Concept for Enhancing

Nuclear Transparency for

Confidence Building in

Northeast Asia

\author{
Man-Kwon Nam \\ Korea Institute for Defense Analyses \\ Seoul, Republic of Korea \\ Sung-Tack Shin \\ Korea Institute for Defense Analyses \\ Seoul, Republic of Korea
}

Cooperative Monitoring Center Occasional Paper/12 


\title{
ii. Sandia National Laboratories
}

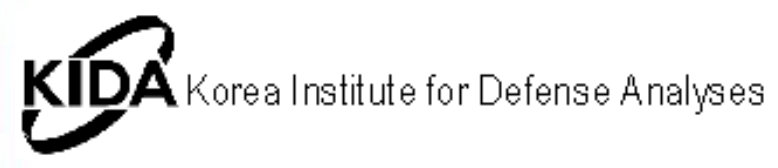

Sandia is a multiprogram laboratory operated

by Sandia Corporation, a Lockheed Martin

Company, for the United States Department of

Energy under contract DE-AC04-94AL85000.

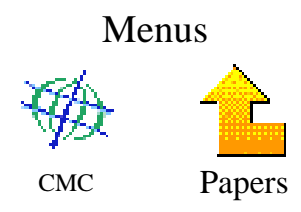

The Cooperative Monitoring Center (CMC) at Sandia National Laboratories assists political and technical experts from around the world to acquire the technology-based tools they need to assess, design, analyze, and implement nonproliferation, arms control, and other cooperative security measures. As part of its mission, the CMC sponsors research on cooperative security and the role of technology. Reports of that work are provided through the Occasional Papers series. Research is conducted by Sandia staff, international technical experts, and visiting scholars. (The CMC's Visiting Scholars Program is administered by the Institute for Public Policy at the University of New Mexico.) For additional information on the CMC's programs, visit the CMC home page on the World Wide Web at <http://www.cmc.sandia.gov> or write to:

Cooperative Monitoring Center

Sandia National Laboratories

Mail Stop 1373

Albuquerque, NM 87185-1373

For specific information on this report contact:

John Olsen at the above address.

This report was prepared by Sandia National Laboratories

Albuquerque, NM 87185 and Livermore, CA 94550

\section{ENTNEA: A Concept for Enhancing Nuclear Transparency for Confidence Building in Northeast Asia}

\begin{abstract}
Nuclear energy continues to be a strong and growing component of economic development in Northeast Asia. A broad range of nuclear energy systems already exists across the region and vigorous growth is projected. Associated with these capabilities and plans are various concerns about operational safety, environmental
\end{abstract}


protection, and accumulation of spent fuel and other nuclear materials. We consider cooperative measures that might address these concerns. The confidence building measures suggested here center on the sharing of information to lessen concerns about nuclear activities or to solve technical problems. These activities are encompassed by an Enhanced Nuclear Transparency in Northeast Asia (ENTNEA) concept that would be composed of near-term, information-sharing activities and an eventual regional institution. The near-term activities would address specific concerns and build a tradition of cooperation; examples include radiation measurements for public safety and emergency response, demonstration of safe operations at facilities and in transportation, and material security in the back end of the fuel cycle. Linkages to existing efforts and organizations would be sought to maximize the benefits of cooperation. In the longer term, the new cooperative tradition might evolve into an ENTNEA institution. In institutional form, ENTNEA could combine the near-term activities and new cooperative activities, which might require an institutional basis, for the mutual benefit and security of regional parties.

\section{Acronyms and Definitions}

\begin{tabular}{|c|c|}
\hline $\mathrm{ABACC}$ & $\begin{array}{l}\text { Brazilian-Argentine Agency for Accounting and Control of Nuclear } \\
\text { Materials }\end{array}$ \\
\hline ASIATOM & Asian Atomic Energy Community \\
\hline ATMS & Authenticated Tracking and Monitoring System \\
\hline CANDU & Canadian Pressurized Heavy Water Reactor \\
\hline CARENET & $\begin{array}{l}\text { Computerized Technical Advisory System for the Radiological } \\
\text { Emergency Net }\end{array}$ \\
\hline CSCAP & Council for Security Cooperation in the Asia Pacific \\
\hline DPRK & Democratic People's Republic of Korea \\
\hline ENTNEA & Enhanced Nuclear Transparency in Northeast Asia \\
\hline EURATOM & European Atomic Energy Community \\
\hline FBR & fast breeder reactor \\
\hline GPS & Global Positioning System \\
\hline IAEA & International Atomic Energy Agency \\
\hline INMARSAT & International Maritime Satellite \\
\hline IRMP & International Remote Monitoring Project \\
\hline $\mathrm{JNC}$ & Japan Nuclear Cycle Development Institute (formerly PNC, see below) \\
\hline KAERI & Korea Atomic Energy Research Institute \\
\hline KEDO & Korean Peninsula Energy Development Organization \\
\hline KEPCO & Korea Electric Power Company \\
\hline KIDA & Korea Institute for Defense Analyses \\
\hline KINS & Korea Institute of Nuclear Safety \\
\hline LWR & light water reactor \\
\hline MOX & mixed oxide \\
\hline NEA & Northeast Asia \\
\hline NPP & Nuclear Power Plant \\
\hline NPT & Non-Proliferation Treaty \\
\hline PACATOM & Pacific Atomic Energy Community \\
\hline PHWR & Pressurized Heavy Water Reactor \\
\hline PNC & Power Reactor and Nuclear Fuel Development Corporation (in Japan) \\
\hline ROK & Republic of Korea \\
\hline SNL & Sandia National Laboratories \\
\hline WANO & World Association of Nuclear Operators \\
\hline
\end{tabular}

\section{Contents}


CMC Paper: ENTNEA: A Concept for Enhancing Nuclear Transparency for Confidence Building in Northeast Asia

1.1 Goals of This Study

1.2 Background of the Nuclear Issues in Northeast Asia

1.3 ENTNEA: A Concept in Information Sharing to Reduce Nuclear Tensions

\subsection{Report Structure}

$\underline{\text { 2.0 Regional Nuclear Industries and Potential Issues }}$

$\underline{\text { 2.1 Regional Nuclear Facilities and Industries }}$

$\underline{\text { 2.2 Potential Issues of the Regional Nuclear Industry }}$

2.2.1 KEDO Reactors

2.2.2 Spent Fuel and Separated Plutonium Storage

2.2.3 Low-Level Waste Disposition

2.2.4 Safety Concerns with Nuclear Reactors

$\underline{\text { 2.2.5 Public Acceptance of Regional Nuclear Industry }}$

3.0 ENTNEA: A Framework for Enhancing Regional Nuclear Transparency

3.1 Basic Concept

3.2 Informal Cooperative Activities for ENTNEA

3.3 A Comparison with Precedents and Other Proposed Regimes

3.4 Methods and Support for Informal Transparency Activities

3.5 Institutional Possibilities for ENTNEA

4.0 Conclusions and Recommendations

APPENDIX: Technological Approaches for Enhancing Regional Nuclear Transparency

$\underline{\text { About the Authors }}$

\section{Figures}

Figure 1. Conceptual Scheme of an ENTNEA Implementation.

Figure 2. Information Flow in the Computerized Technical Advisory System for the Radiological Emergency Net (CARENET).

Figure 3. Monthly Status of Environmental Radiation Count Rates Shown in a Korea Electric Power Company (KEPCO) Pamphlet.

Figure 4. Status of Airborne Count Rate Measurements Shown in a Kansai Electric Power Company (Japan) Quarterly Report on the Company Website.

Figure 5. Seaborne Application of the ATMS Tracking System to Provide Location, Safety, and Security Information in Near-Real Time.

Figure A-1. A Solar-Powered Gamma-Ray Measurement Station near Los Alamos National Laboratory

Figure A-2. Remote Monitoring of Spent Fuel Storage in Australia 


\section{ENTNEA: A Concept for Enhancing Nuclear Transparency for Confidence Building in Northeast Asia}

\subsection{Introduction}

\subsection{Goals of This Study}

In Northeast Asia, the publicly stated consensus on economic recovery and growth urges continued development of nuclear energy technologies to provide power for this growth. However, highly developed nuclear technical capabilities may lead to concerns about potential proliferation of nuclear weapon capabilities. Therefore, measures to increase the transparency of nuclear activities in Northeast Asia offer particular promise for improving perceptions of regional security while maintaining economic growth.

This report examines potential benefits of increased nuclear transparency and suggests cooperative means to realize those benefits. We will consider measures that might be applicable to reactors and other fuel cycle facilities in South and North Korea, Japan, China, far eastern Russia, and Taiwan. For the purpose of establishing regional interest in enhanced transparency, issues of environmental protection and operational safety may be as relevant as material protection and nonproliferation. Considering the relatively brief history of transparency discussions in Northeast Asia, we will look forward twenty years, which corresponds approximately to national nuclear planning time scales.

Present and historical military tensions in Northeast Asia provide a setting in which nuclear weapon proliferation must be taken as a serious concern. Three acknowledged nuclear powers, China, Russia, and the United States, play active roles. Two states, Japan and South Korea, have advanced nuclear industries. Another state, North Korea, has entered into an agreement with the United States to freeze its alleged nuclear weapon program. In addition, Taiwan operates its own nuclear power plant system. This mix makes it easy to envision unstable dynamics. Historical tensions that might cause nuclear proliferation in Northeast Asia stem from the period of Japanese domination before 1945, the separate government of Taiwan since 1949, and the unresolved Korean armistice of 1953. Other issues can act as potent irritants: resource scarcity, competition for markets, and the environmental consequences of rapid economic growth.

Cooperation in peaceful nuclear activities offers substantial prospects for managing and reducing tensions that can result from worst-case considerations of nuclear capabilities or accident scenarios. Previous studies $(1,2)$ have discussed some of the major challenges and identified cooperative opportunities in general. This study by the Korea Institute for Defense Analyses (KIDA) focuses on more specific measures by considering regional perceptions and priorities from a South Korean perspective. We will explore these ideas by examining current transparency measures, weighing potential benefits of expanded transparency, and suggesting mechanisms that might provide the desired transparency. In particular, we emphasize technical means for sharing information that might be relevant to building confidence in safety, environmental protection, and nonproliferation.

We have benefited from many technical discussions with several staff members $\underline{(3)}$ of Sandia National Laboratories in writing this paper.

\subsection{Background of the Nuclear Issues in Northeast Asia}

Rapid economic growth requires vast expansion of energy sources to power factories, light cities, and transport raw materials and finished products. Part of this expanded power supply will be met by nuclear plants, bringing various nuclear safety and nonproliferation issues to the fore. Large-scale nuclear industries necessarily develop a broad range of engineering capabilities that can suggest an inherent potential for proliferation of nuclear weapons. This potential can increase tensions despite declarations of peaceful intentions. Rapidly growing industries also introduce concerns about the consequences of unsafe operations for public health and the environment.

Nuclear transparency as a tool for improving regional security is a relatively new concept. Previously, nuclear transparency in Northeast Asia was limited to meeting the requirements for safeguards of nuclear materials as called for in the Treaty on the Non-Proliferation of Nuclear Weapons (NPT). These safeguards, under the International Atomic Energy Agency (IAEA), are comprehensive and rigorous. The results of IAEA safeguards inspections are, however, confidential between the IAEA and the 
respective states. The purpose of this report is to suggest that additional transparency, beyond IAEA safeguards, could be useful in improving regional security and confidence in the nonproliferation regime.

With the 1992 Joint Declaration of the Denuclearization of the Korean Peninsula(4), nuclear technology became an important part of security discussions. Both Koreas agreed not to separate plutonium or enrich uranium and the agreement includes provisions for transparency by means of mutual inspections between South and North Korea.

This process continued when the United States and North Korea negotiated the Agreed Framework (5) to freeze the alleged North Korean nuclear weapon program in exchange for two light water reactors (LWRs) in 1994. More recently, several proposals $\underline{(6)}$ have sought to institutionalize nuclear transparency and cooperation in some form under a name like ASIATOM (Asian Atomic Energy Community) or PACATOM (Pacific Atomic Energy Community).

Nuclear reactors themselves may be a source of tension and, hence, should be examined for transparency opportunities. Concerns involving reactors fall into two general categories: (1) material diversion for proliferation and (2) operational effects on safety and the environment. Although the IAEA safeguards program(7) is the primary guard against diversion, additional transparency can improve perceptions of material protection and accountancy. Moreover, operational transparency can address both domestic and international concerns about safety and environmental protection.

Disposition of radioactive waste and storage of spent fuel from reactors is another critical area where transparency cooperation can be important. Known as the "back end" of the fuel cycle, these activities can raise concerns $\underline{(8)}$ about unsafe transportation, leakage into water systems, and vulnerability to unauthorized access. Even in the absence of actual problems, perceptions of differing (or unknown) environmental standards can occasion strong regional protests.(9) Although no nuclear industry has mastered all of the problems associated with the back end of the fuel cycle, technical options for reducing the "back-end" concerns exist and are noted in Section 3.2.

Environmental sampling methods may be useful for enhanced nuclear transparency. National air and water monitoring systems gather environmental information for public safety, including radiation and toxic waste levels, some of which is not specific to a particular site. Because the environmental measuring systems are relatively non-intrusive, these data are less sensitive and may be more sharable. Moreover, the IAEA is starting to implement new environmental sampling techniques, $(10)$ mainly water sampling, as part of the Strengthened Safeguards System. Regional parties could collaborate in development and implementation of such techniques, either for nonproliferation or environmental protection goals.

\subsection{ENTNEA: A Concept in Information Sharing to Reduce Nuclear Tensions}

Our approach to the security problems occasioned by nuclear industries is to reduce tensions by sharing information. Sharing selected information can help prevent proliferation threats by raising the probability of eventual discovery of covert activities. Better information flow can also help a country avoid responding to a nonexistent threat. Furthermore, sharing information regarding safety and environmental concerns can reduce uncertainties when industries are actually safe and identify areas for cooperative improvements where concerns prove to be justified.

The breadth of issues and number of industries with common problems suggest that a regional institution might offer an effective mechanism to enact transparency measures. While ultimately we conceive of an institution, we foresee that a regional tradition of cooperation is needed first. Therefore, we suggest various activities in information sharing that we characterize as natural steps of enhanced nuclear transparency leading toward a regional institution. We give this institution the working name of Enhanced Nuclear Transparency in Northeast Asia (ENTNEA). ENTNEA as an institution may be the final goal; ENTNEA as a concept may be the overall process of preliminary activities evolving into the final institution.

Information sharing may occur through document exchanges, visits and inspections, or by technical means. These methods offer a wide range of options to achieve various levels of transparency. The method may be selected to reflect the goals of a transparency agreement. For instance, an initial stage might depend on simple visits to facilities and exchange of general documentation. Greater transparency for a narrowly defined purpose, such as obtaining baseline radiation levels, might follow and could be based on transmission of some operational data. Thus, the transparency process selects goals for tension reduction and shares information that can help solve problems stemming from uncertainties and worst-case concerns.

We use the term cooperative monitoring $\underline{(11)}$ for this process. In our definition, information sharing involves mutual agreement between parties. We also stipulate in this terminology that all parties to an agreement have access to the shared data and, if technical means are used to acquire the data, that the technology itself be sharable. Furthermore, the transparency measures considered here must include a process to resolve discrepancies or contradictions arising from the shared data. This is the underlying procedural process that we use when discussing enhanced nuclear transparency.

$\operatorname{ASIATOM}(12)$ and $\operatorname{PACATOM} \underline{(13)}$ are alternate proposals for reducing nuclear tensions. These concepts would rely upon regional management of critical elements of the nuclear fuel cycle. In some respects ASIATOM and PACATOM appear to be modeled upon the EURATOM (European Atomic Energy Community) precedent; however, the goals are quite different. Whereas EURATOM sought to build a nuclear industry in Europe in the 1950s, the ASIATOM and PACATOM concepts would attempt to establish new controls over existing industries in Asia. By comparison, ENTNEA, by emphasizing information sharing rather than management, may be more practical from the standpoint of political acceptability. Nevertheless, a successful ENTNEA could pave the way for ASIATOM and PACATOM concepts in the future.

\subsection{Report Structure}

In this report we summarize the nuclear industries of Northeast Asia and enumerate some areas of concern. Concerns exist at various 
levels of urgency. Some concerns seem merely hypothetical, compared to others that reflect actual experience. The variety of topics is intended to suggest that transparency steps exist at many levels. All regional nuclear industries can be involved potentially in various areas of concern, which include safety and nonproliferation at enrichment and reprocessing plants, reactors, spent fuel storage sites, and waste disposition sites.

A tradition of cooperation could start with low-level concerns and build toward more critical problems in a step-by-step fashion. We suggest an experimental, informal approach in several topic areas to develop a regional foundation in cooperation. ENTNEA, an institution that might grow from such a series of cooperative activities, is compared to other cooperative regimes and precedents.

Recognizing that agreements to share data and the resources to carry out such agreements cannot exist in a vacuum, we suggest some organizational modes for supporting these efforts. Organizational mechanisms ranging from unofficial (engineering organizations) to official (ministries) offer a variety of support and authority from which parties may select. Next, we discuss ideas about the requirements for an ENTNEA institution, which could be a means for consolidating and expanding the transparency activities.

We conclude by noting which hypothetical activities might be discussed or implemented as starting points in the near future. Considering the relatively brief history of transparency discussions in Northeast Asia, we will look forward in a time frame of about twenty years, which corresponds approximately to the time scale for national nuclear planning. Appropriate official and unofficial discussion tracks are invited to consider these suggestions.

Specific ways to acquire and share the relevant information are stated in the appendix. These technologies could support the information-sharing requirements of the suggested activities of Section 3. Various technical and administrative approaches are analyzed for capabilities, limitations, and, inevitably, cost and intrusiveness constraints.

\subsection{Regional Nuclear Industries and Potential Issues}

\subsection{Regional Nuclear Facilities and IndustrieS}

The nuclear energy systems of Northeast Asia encompass many civilian nuclear reactors. The reactors of regional states are mostly LWRs, with some pressurized heavy water reactors (PHWRs) and fewer fast breeder reactors (FBRs). In addition to the reactors currently operating, many reactors are now under construction and additional reactors are in planning. Regional states are counting on nuclear energy as a major factor in their economic growth.

The scope of the civilian reactor complex is summarized in Table 1. For the purposes of this study, regional states in Northeast Asia are South Korea, North Korea, Japan, China, and Russia. We include the United States as an interested party and potential cooperative partner. North Korea is included since it will have two LWRs totaling 2000 MWe. These are currently under construction by the Korean Peninsula Energy Development Organization (KEDO) as stipulated in the 1994 Agreed Framework. Taiwan also could participate in the cooperative measures of this study. Finally, we note that of Russia's large reactor system, only four small units are in East Asia.

Japan has the most comprehensive nuclear energy system, with 53 nuclear reactors(14) providing $33 \%$ of their electricity. Over the next dozen years, Japan hopes to increase its nuclear power capacity by 60 to $75 \% .(15)$ Energy security is an important stated goal;

(16) hence Japan has developed the full fuel cycle, including reprocessing of spent fuel to obtain plutonium.(17)

Table 1. Status of Nuclear Power Systems in Northeast Asia and the United States

\begin{tabular}{|l|c|c|c|c|c|c|}
\hline \multicolumn{1}{|c|}{ Systems } & \multicolumn{2}{|c|}{ Operation } & \multicolumn{2}{c|}{ Construction } & \multicolumn{2}{c|}{ Planning } \\
\hline & Units & Power(10MWe) & Units & Power(10MWe) & Units & Power(10MWe) \\
\hline $\begin{array}{l}\text { United } \\
\text { States }\end{array}$ & 110 & 10,437 & 0 & 0 & 0 & 0 \\
\hline \hline Japan & 53 & 4,417 & 2 & 218 & 2 & 193 \\
\hline Russia & 29 & 2,124 & 4 & 360 & 15 & 902 \\
\hline $\begin{array}{l}\text { South } \\
\text { Korea }\end{array}$ & 12 & 1,032 & 4 & 540 & 2 & 200 \\
\hline Taiwan & 6 & 515 & 0 & 0 & 0 & 0 \\
\hline China & 3 & 227 & 2 & 120 & 10 & 940 \\
\hline
\end{tabular}




\begin{tabular}{|l|c|c|c|c|c|c|}
\hline $\begin{array}{l}\text { North } \\
\text { Korea }\end{array}$ & Defueled & 0.5 & 2 & 200 & 0 & 0 \\
\hline
\end{tabular}

South Korea's nuclear industry is growing rapidly and experts expect(18) that nuclear power will provide the majority of their electrical needs by roughly 2010. In accordance with the Denuclearization Agreement, South Korea does not have all components of the fuel cycle. However, the South Korean industry is mature and capable of undertaking the technical lead for the KEDO reactors in North Korea.

Although China has had nuclear weapons for three decades, nuclear power generation is a relatively recent capability. According to reports, China plans to quadruple(19) their nuclear power output by 2003 and build many $(20)$ more reactors over the coming decades. In addition, China is also considering the expansion of research facilities for the plutonium fuel cycle. (21)

Taiwan has six nuclear reactors that supply one third of its electrical power. Although Taiwan is not a state party to the NPT, all of the reactors are under IAEA safeguards. Taiwan has no plans for new nuclear plants pending solution of problems concerning disposal of waste and storage of spent fuel. Most of Taiwan's research efforts concentrate on waste disposal and safety.

North Korea has removed the fuel from their single reactor in exchange for two large reactors under the 1994 Agreed Framework. Those reactors will be under IAEA safeguards and are targeted for completion in 2003.

The United States is included in Table 1 as an interested observer and possible participant in any nuclear transparency activities in Northeast Asia. With the largest nuclear power system in the world, the U.S. has no planned new construction. Nevertheless, the U.S. nuclear industry is still competitive and leads the world in certain areas.

Finally, the Russian system is mainly in Europe, with four small heating and electricity reactors near the Arctic Circle at Bilibino in Siberia. Nevertheless, Russia can play a part in nuclear transparency in Northeast Asia, because it is supplying two new reactors to China at Lianyungang and cooperating with Japan and South Korea on a waste disposal problem.

\subsection{Potential Issues of the Regional Nuclear Industry}

The nuclear industry in Asia is growing while the overall nuclear industry in the world has stagnated. Most Asian states pursue development policies that place a high priority on nuclear energy as a means to meet their requirements for electrical power. Currently, the nuclear industry in Asia represents one fourth of the world's total nuclear power. It is expected to increase to one third in the early 21 st century. If this growth trend in the Asian industry continues, several issues regarding nuclear activities may arise. In the following sections below we highlight those issues on which transparency cooperation may be helpful.

\subsubsection{KEDO Reactors}

The 1994 Agreed Framework between the United States and North Korea froze the North Korean nuclear program in exchange for two LWRs capable of producing a total of 2,000 MWe. While this landmark agreement has succeeded in its immediate goal to neutralize a potential nuclear weapon program, it also raises several issues.

The first priority, since the Agreed Framework was a nonproliferation measure, is to assure that the LWR technology is not used for proliferation purposes, despite IAEA safeguards. Would an additional agreement to share confidential IAEA information with selected regional parties reduce tensions between North Korea and South Korea or Japan? Are there transparency measures supplemental to safeguards that might reduce concerns?

The second issue is the nuclear safety issue. Normally, training operators in a new, complex technology is a major task. So far, North Korea is reluctant to hold training in South Korean territory. Building a reactor simulator facility for training in Sinpo, North Korea, would escalate costs and limit trainees' exposure to procedures at actual facilities. The Gori Operation Training Center in South Korea could provide better, far less expensive training. This is still in negotiation.

\subsubsection{Spent Fuel and Separated Plutonium Storage}

Fuel rods removed from a reactor, known as spent fuel, are highly radioactive and contain plutonium. Thus, spent fuel carries with it safety and proliferation concerns. Reprocessing to separate the plutonium for future use in reactors increases the proliferation concern during the time after the reprocessing has occurred and before the fabrication of new fuel rods.

South Korea has the problem of disposing of spent fuel from its reactors. Four LWR complexes currently are faced with the prospect of stopping the production of electricity because of the shortage of interim storage sites for the spent fuel. In accordance with international nonproliferation policy, South Korea does not reprocess spent fuel, which could reduce the storage problem. Currently, South Korea is enlarging waste storage facilities and developing related technologies, but spent fuel remains a problem.

The United States also must solve the spent fuel disposition problem. The U.S. effort in spent fuel disposition is the Yucca Mountain Project, but this has not accepted any nuclear waste yet.

Japan is faced with similar difficulties in dealing with spent fuel disposition because of a shortage of waste storage facilities. The Japanese problem is further compounded by accidents that have damaged their technical and managerial reputation. Arguing that a closed fuel cycle is a basic element of energy security, Japan has for years projected a future nuclear power system in which plutonium created in LWRs would be separated and recycled as fuel.(22) Consistent with this policy, the Japanese have separated plutonium from fuel rods withdrawn from LWRs. They have accumulated about 10.8 metric tons of fissionable material (4.6 tons 
within the country and 6.2 tons in England and France).(23) The material is under IAEA safeguards and is earmarked for eventual use as reactor fuel.

Regional states have expressed concern that Japan has accumulated an excessive amount of plutonium, which could be usable for a nuclear weapons program.(24) Japanese nuclear experts are aware of this concern and have expressed interest in finding effective and politically acceptable transparency measures to reassure their neighbors.

In response to these shared issues of spent fuel and separated plutonium, Northeast Asian systems are discussing the establishment of a multilateral cooperative regime on the peaceful uses of nuclear energy. One proposal, $(25)$ for example, suggests regional storage of spent fuel in Russia, under IAEA safeguards, for periods of 50 to 100 years. Discussions of a PACATOM or an ASIATOM often feature the problem of spent fuel disposition and consider cooperative management as a potential solution.

\subsubsection{Low-Level Waste Disposition}

Low-level waste from a nuclear power plant (NPP) is typically contaminated protective clothing, tools, and cleaning materials. It can accumulate rapidly in the course of routine maintenance of reactors or other nuclear facilities. Another source of low-level waste is the decommissioning of shutdown reactors and retired nuclear submarines. This problem is a general and difficult issue for regional states to overcome.

Taiwan has tried to dispose of its overflowing low-level waste in North Korea; South Korea has protested the lack of planning for transportation emergencies for seaborne shipments and questioned the environmental planning of the North Korean site. Until these safety issues can be resolved, Taiwan has put this undertaking on hold.

South Korea and Russia continue to discuss low-level waste storage in Russia; this would depend upon identifying and characterizing sites in Russia. Some South Koreans are concerned that such a proposal has only a small chance of success, because of the special sensitivity of nuclear waste. Therefore, South Korea still considers that it must develop and implement a waste disposal policy internally.

Decommissioning of an aging fleet of Russian nuclear submarines has resulted in the accumulation of radioactive waste, both highand low-level. Low-level liquid radioactive waste has leaked from submarines during maintenance and decommissioning; Russia dumped some of this radioactive waste into the East Sea (Sea of Japan) in 1993.(26) Under Republic of Korea (ROK)-Russia and Japan-Russia agreements,(27) waste handling and storage equipment is being provided to Russia. The United States has provided additional technical support to Russia. However, because of the Russian economic conditions, waste handling continues to be a problem.

\subsubsection{Safety Concerns with Nuclear Reactors}

Despite some highly publicized incidents in the Japanese industry, most observers believe that the Asian nuclear industry operates competently and safely. Nevertheless, Japan and South Korea are concerned about the effects of an accident, even in another country, both as an immediate public safety threat and also as a cause to reverse public acceptance of nuclear power.

Part of this concern is related to expansion of the newer nuclear industries. China, currently having three power reactors, is planning to greatly expand its nuclear power system in the coming decades. North Korea is receiving two full-size NPPs, but only has operating experience with a small research reactor. These two states face enormous training and experience challenges. Thus, in North Korea and China, developing a "safety culture" is an important challenge. We note that China has cooperated with the IAEA and with World Association of Nuclear Operators (WANO) safety teams and is acting on their suggestions.

WANO and the IAEA both conduct valuable programs in nuclear safety, which could be expanded or supplemented by regional activities as noted in the next chapter.

\subsubsection{Public Acceptance of Regional Nuclear Industry}

Nuclear industries in Northeast Asia are growing more rapidly than in other regions of the world. For the most part, public concern about environmental issues is increasing and public opinion over safety problems of NPPs is becoming more critical. Thus, each state is faced with difficulty in locating new NPPs, fuel cycle facilities, and radioactive waste disposition sites. Furthermore, safety issues are often raised regarding transportation of nuclear material, sometimes for political reasons. Without the sharing of relevant information between the government and public, these problems cannot be resolved.

The positive side of nuclear power needs greater prominence also. The regional industry should communicate to the public the role for nuclear power in supporting economic growth and as a means to meet greenhouse gas reduction standards.

In the next sections we examine potential transparency measures that could address these areas of concern. A potential institution to administer these measures might result eventually; we consider its potential contribution, as well.

\subsection{ENTNEA: A Framework for Enhancing Regional Nuclear Transparency}

\subsection{Basic Concept}

Nuclear industries in Northeast Asia could enhance nuclear transparency by sharing information related to the issues noted in the preceding section. In sharing this information, states could (1) build confidence in their neighbors' ability to operate NPPs safely and protect nuclear material, and (2) obtain information that would be useful in enhancing their own performance in these areas. 
We envision a process for Enhanced Nuclear Transparency in Northeast Asia (ENTNEA) in the region to turn the above concept into reality. While ENTNEA may ultimately result in an institution for regional cooperation, the general lack of a tradition of regional institutions makes that an unlikely first step. As implied by the flow chart in Figure 1, developing a cooperative tradition of individual, informal measures might form a foundation for an institution over a period of time. Moreover, the informal process could start up gradually, each project providing the basis for the next cooperative activity. Of the various opportunity areas discussed in the next section, probably the least exciting options would be the first to be politically acceptable. Over time, however, these various cooperative activities might provide the basis for more comprehensive activities, such as an ENTNEA institution.

\section{Figure 1. Conceptual Scheme of an ENTNEA Implementation}

\section{ENTNEA CONCEPT}

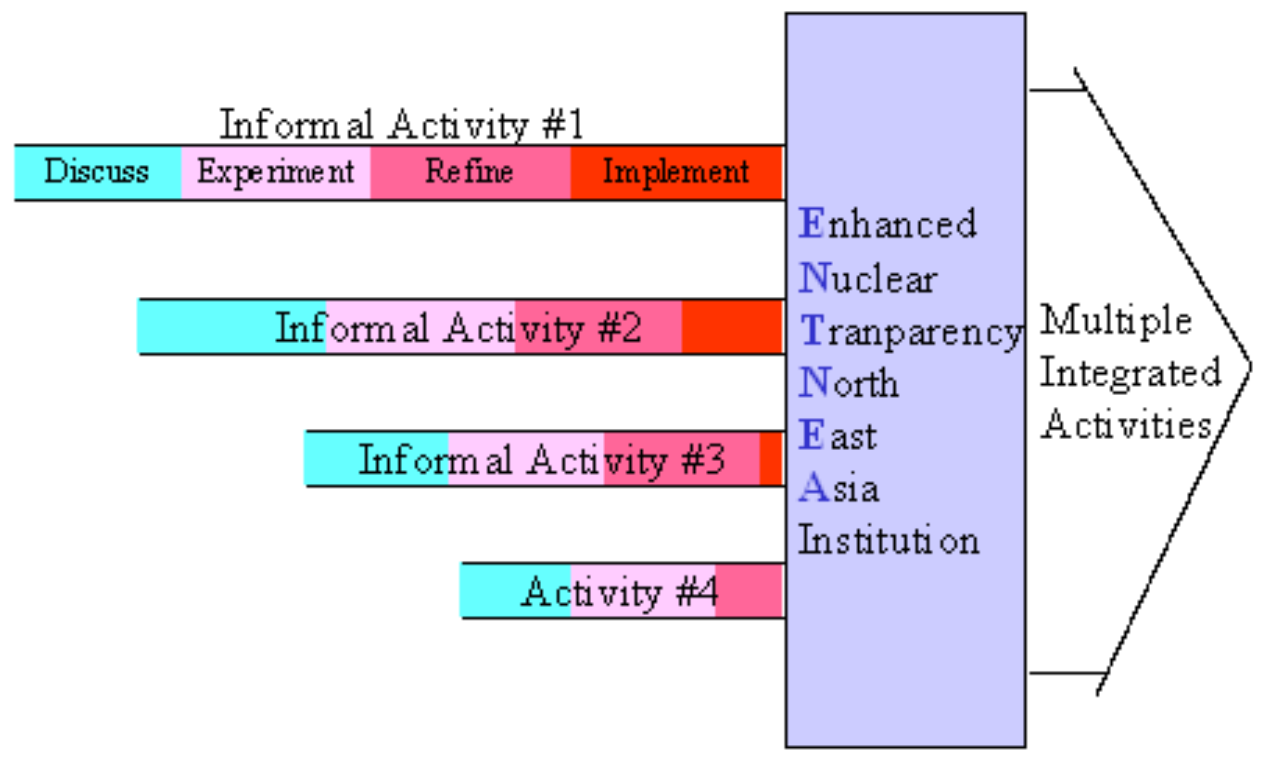

\section{Informal information-sharing activities lead to an institution, which can evolve to include more comprehensive forms of cooperation.}

As an institution, ENTNEA could undertake more comprehensive regional cooperation, in addition to administering the continuing informal efforts. In the final part of this chapter, we consider what this institution might look like. The ENTNEA institution would have to evolve in cooperation with existing international programs of the IAEA, industry groups, and governments. Depending upon regional preferences, the institutional form of ENTNEA might perform certain analysis functions and help organize regional research in pressing issues like waste disposition.

\subsection{Informal Cooperative Activities for ENTNEA}

Regional nuclear transparency activities could build a tradition of nuclear cooperation in limited and specific areas of common interest. Informal, cooperative activities among regional states for ENTNEA could form a step-by-step approach leading eventually to an institution. Cooperative activities could be bilateral or multilateral, with the goal of including all regional parties eventually. Initial ENTNEA activities could be noninstitutional in format and endorsed by appropriate government agreements.

Cooperating partners for transparency could be drawn informally from technical organizations. Some of the activities might be academic or research exchanges. Each activity would pass through discussion, experiment, refinement, and implementation phases, as shown in Figure 1. Some activities might have specific lifetimes; longer-term activities might be absorbed by an ENTNEA institution. Suggested candidate transparency activities are listed in this section. The order of discussion is not intended to be chronological, nor is there a one-to-one mapping to the issues of concern.

Specific ways to acquire and share the relevant information are stated in the appendix. Various technical and administrative approaches are analyzed for capabilities, limitations, and the constraints of cost and intrusiveness.

\section{Environmental Radiation Monitoring}

Enhancing nuclear safety through wide-area monitoring of environmental radiation could address concerns about reactor safety, waste deposition, and public acceptance. There could be direct benefits to public health and emergency response in case of an accident; communications for prompt data sharing would be key to cooperation. Research in modeling for air transport of pollution would also be useful, but this would only require document sharing among researchers. Because environmental radiation monitoring is not intrusive and is in the interest of public safety, this may be a feasible informal activity. 
CMC Paper: ENTNEA: A Concept for Enhancing Nuclear Transparency for Confidence Building in Northeast Asia

There are already precedents in the region of making more environmental radiation data available. In South Korea, the Korea Institute of Nuclear Safety (KINS) is preparing an Internet-based system to acquire and distribute data from the nationwide monitoring system, IERNet. IERNet includes 16 national monitoring posts. This data will be integrated with safety data from the Korean NPPs (acronym: SIDS), meteorological data (acronym: REMDAS), and consequence modeling (acronym: FADAS) to form a comprehensive emergency response system, to be known as CARENET (Computerized Technical Advisory System for the Radiological Emergency Net).(28) The information flow is shown in Figure 2.

The regional utilities also release information in various ways. The Korea Electric Power Company (KEPCO) pamphlet in Figure 3 shows a monthly report of radiation near eight NPP sites. High and low dose rates are listed for seven; the eighth was shut down for refueling at the time of the report. Similarly in Japan, Kansai Electric displays monthly radiation summaries on their Internet site. Figure 4 shows highs and lows for three months at the eleven Kansai NPPs. These examples suggest that the nuclear industry may be prepared to publish environmental radiation data and might participate in an organized effort, which could provide data in a common format with explanatory information.

Figure 2. Information Flow in the Computerized Technical Advisory System for the Radiological Emergency Net (CARENET).

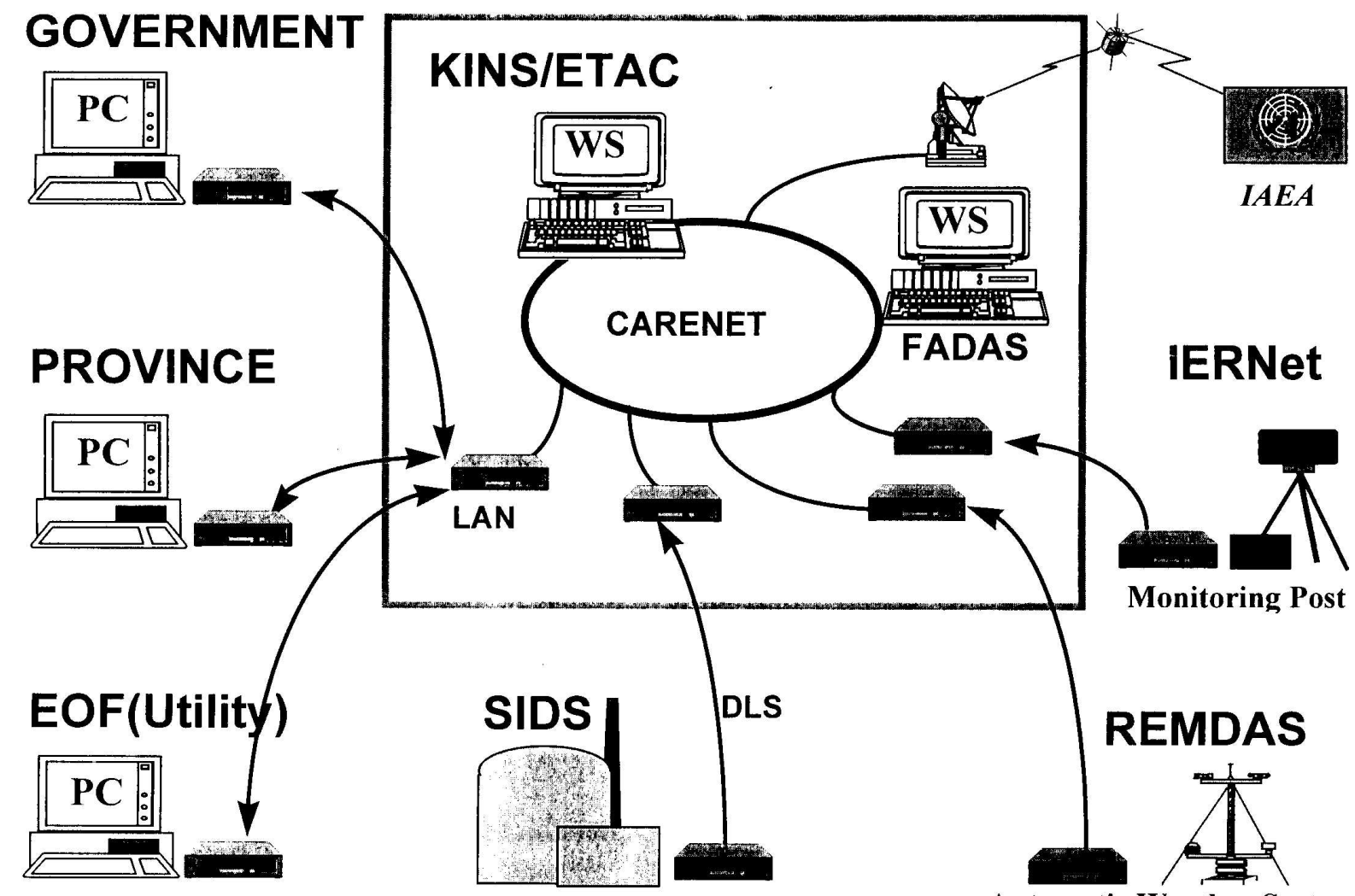

${ }^{\star}$ EOF:Emergency Operation Facility

Safety Parameters

Automatic Weather System

Figure 3. Monthly Status of Environmental Radiation Count Rates Shown in a Korea Electric Power Company (KEPCO) Pamphlet. 


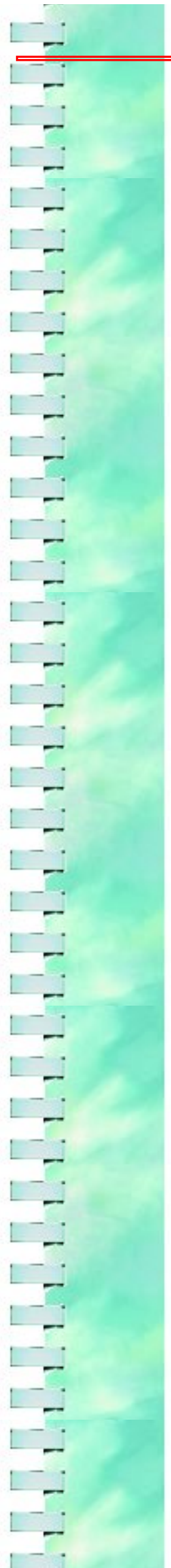

원전인근지역 환경관리

환경방사선량률 측정현황

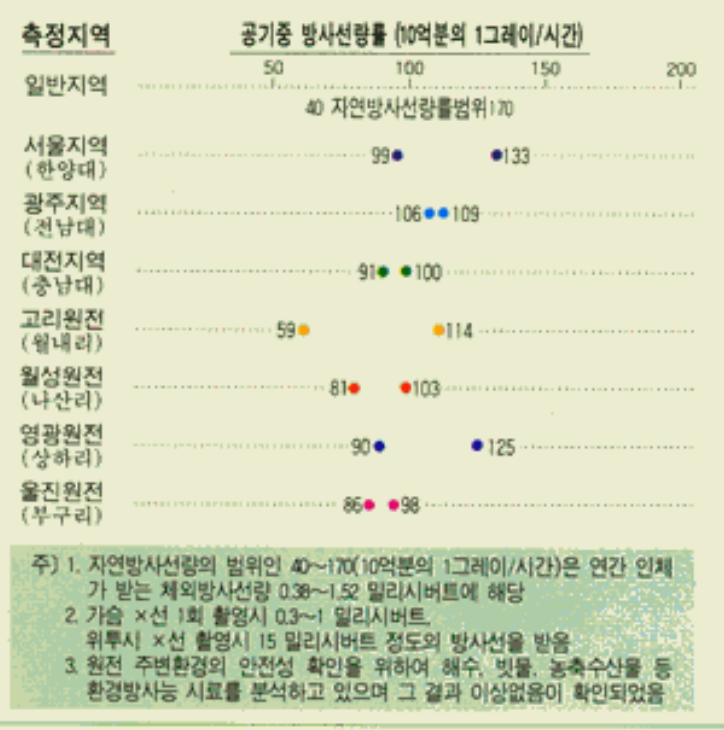

방사물 발생량

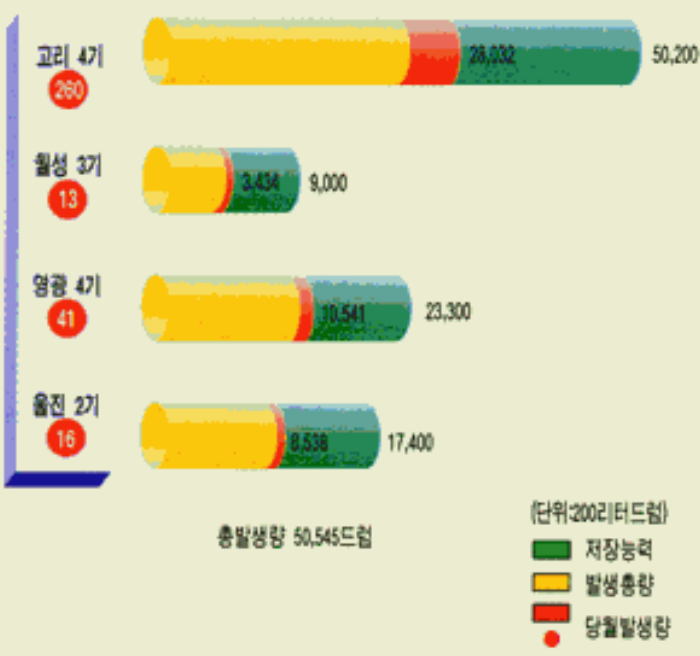

\section{Spent Fuel and Separated Plutonium Storage}

Transparency in spent fuel and separated plutonium storage could reduce certain proliferation concerns. Because IAEA safeguards results are protected as confidential, sharing of inspection results or other monitoring arrangements could be an important factor in regional confidence building. The separated plutonium issue has already received some attention. In high-level talks with Japan in 1995, South Korea proposed discussions about the total amount and isotopic content of plutonium accumulated in Japan. Having been raised at a high political level, enhanced plutonium transparency might be a promising topic for cooperation on the technical levels. However, this might not be an initial regional activity because not all systems have separated plutonium. If consideration is expanded to include spent fuel, then all systems might participate.

A promising technical means for enhancing spent fuel and plutonium transparency might be drawn from the International Remote Monitoring Project (IRMP).(29) In the IRMP, movement, intrusion, and video sensors can provide dial-up information to authorized users. This type of system could provide relatively nonintrusive means for Japan to broaden the transparency of its stocks of separated plutonium. In exchange, other countries might offer transparency in spent fuel storage using this same technology. The appendix offers further discussion and an example of an installation in Australia.

Figure 4. Status of Airborne Count Rate Measurements Shown in a Kansai Electric Power Company (Japan) Quarterly Report on the Company Website. 


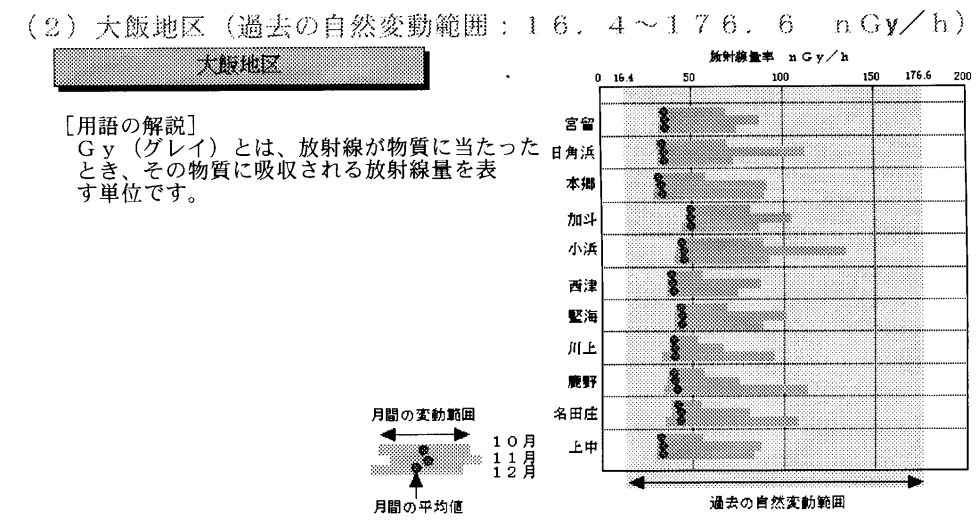

(帮倍: $: \mathrm{n} \mathrm{G} / \mathrm{n}$ )

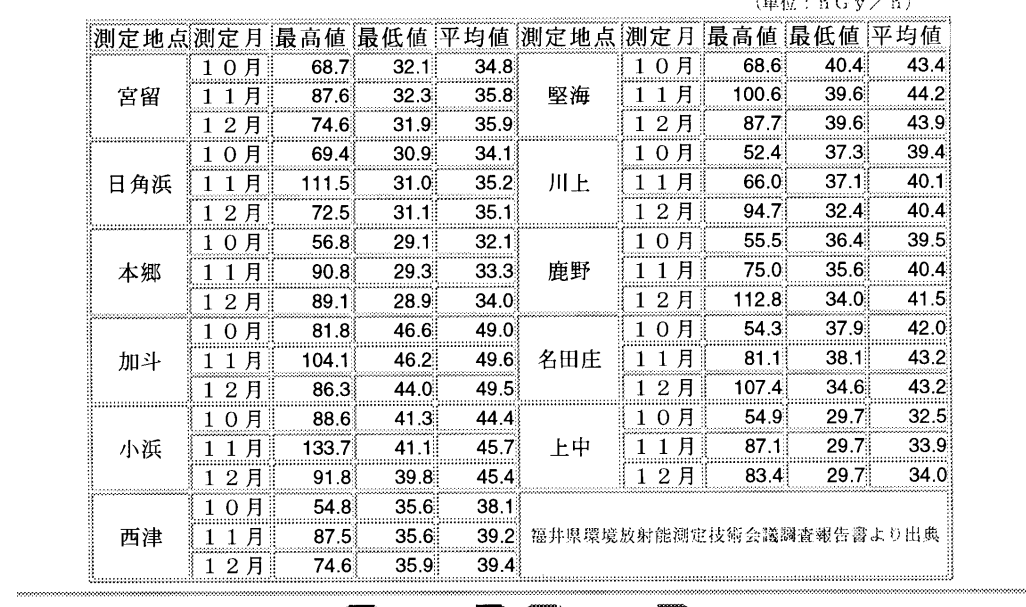

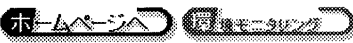

\section{Transparency for Nuclear Reactors}

International concern about reactor safety and nonproliferation compliance can be addressed by enhanced transparency. Many transparency options exist in modern reactors, where hundreds of data channels are monitored continuously. Many of these channels convey routine information with no sensitive content. While safety cannot be proven to a skeptical public, sharing selected information can show that NPPs are operating within their normal design limits. Nonproliferation concerns can also be addressed by showing that an unscheduled refueling is not occurring.

Enhancing transparency for the KEDO LWRs would be particularly beneficial to South and North Korean relations. Transparency in the KEDO LWRs is of great interest to South Korea, as a supplement to the IAEA safeguards that will be in place. Since the KEDO LWRs will be South Korean model reactors, North Korea could cooperate with South Korea on operations of the reactors. As operator and vendor, respectively, North and South Korea could ensure the normal operations of reactors and build mutual confidence through sharing information about operations of LWRs. Exchange of data about safe operating procedures could be particularly important during refueling, when the need to complete refueling promptly puts additional pressure on the operators. Of course, this is the time when material diversion concerns are the highest.

KEDO already has devised a protocol through which data on reactor operations can be exchanged via sophisticated communications systems and video images. South Korean workers in Sinpo, North Korea, are currently constructing communication systems between KEPCO and KEDO offices in Seoul, South Korea, and the construction site in Sinpo. Once the reactors are operational, a transparency measure could take advantage of the communications link to transmit data from the control room of LWRs in Sinpo to the KEDO office in Seoul. The appendix examines transparency opportunities at reactors in more detail.

\section{$\underline{\text { 4. Nuclear Safety Conventions }}$}

Nuclear safety conventions under the auspices of the IAEA address several safety and nonproliferation concerns noted above. For example, under the Convention on Early Notification of a Nuclear Accident,(30) the IAEA can provide immediate technical and administrative response after notification of a nuclear accident. Exchange of information to show compliance with these conventions could be a transparency measure.

Cooperation in designing and implementing an automatic notification system would strengthen the convention and be a confidence building measure. In this case, the ENTNEA activity would supplement the existing IAEA convention, at least on a regional basis. This is a potential area for early ENTNEA cooperation, as regional parties have signed the convention already (see the appendix).

\section{$\underline{\text { 5. Transportation Safety }}$}

Routine operations in the fuel cycle require movement of fuel assemblies to the reactors and subsequent transportation of the spent 
fuel for storage, reprocessing, or final disposition. Both domestic and regional objections have been voiced about shipments, despite rigorous safety processes. Therefore, nuclear material transportation safety could also be a topic of regional cooperation. Cooperative monitoring of nuclear material transportation could enhance national programs to protect nuclear material and improve public perceptions of safety. Exchange of near-real-time information could also aid regional response in case of an emergency or accident. Further discussion in the appendix addresses the need to protect some parts of this data from misuse.

Recently, the Authenticated Tracking and Monitoring System (ATMS),(31) developed by Sandia National Laboratories, demonstrated successful monitoring of a sea shipment of uranium ore from Australia to Europe. (Figure 5 shows an example of a seagoing application.) Commercial communication systems supported frequent reporting of the shipment location and integrity as it went halfway around the world. Application of this type of technology to future global shipments could contribute to safe transportation of nuclear material. It could also address international concerns about the safety of these shipments.

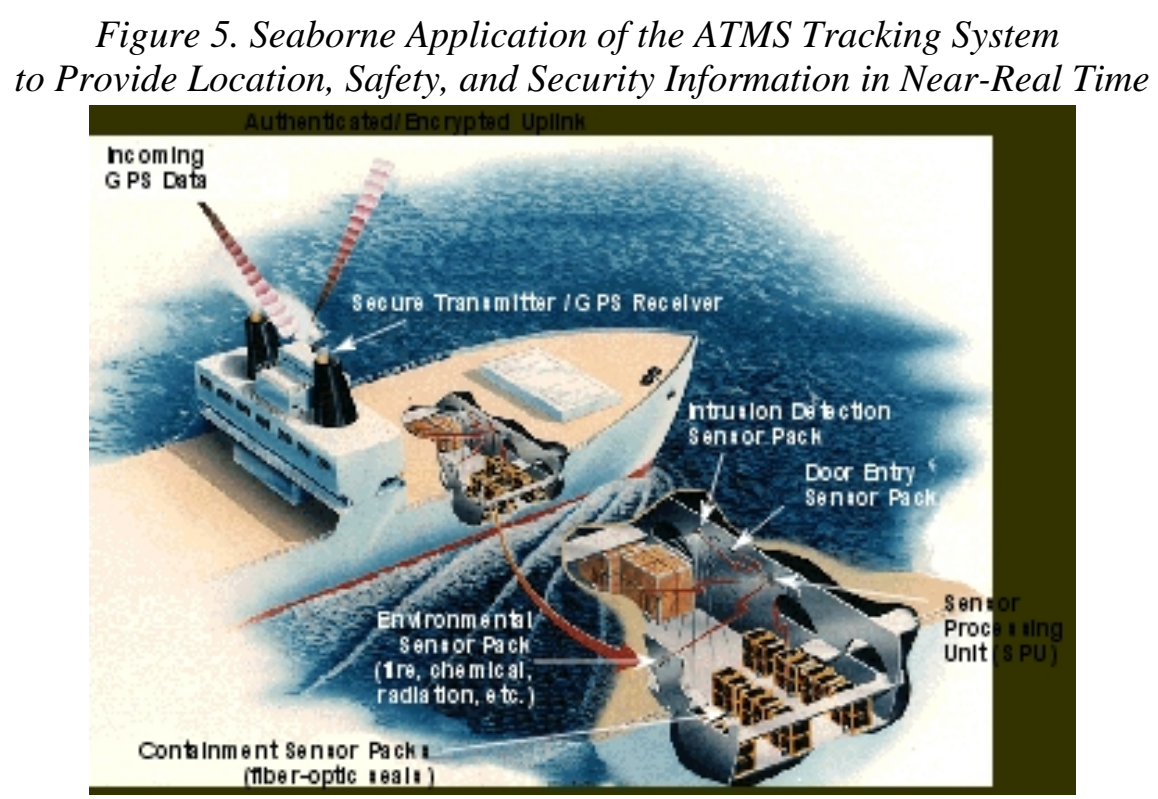

The preceding discussion briefly summarized ideas for five cooperative projects. In the appendix, we expand on this discussion and elaborate on the process of selecting information for transparency. The criteria we use will consider the relevance of available information to the nuclear concern, how it could be transmitted, and who might receive this information. We also attempt to evaluate the benefits and costs of engaging in each cooperative process, including the risks associated with loss of control of data.

These ideas for cooperative activities could build a regional experience in nuclear transparency. Success with these activities could build the rationale for an institutional cooperation. An eventual ENTNEA institution could absorb these activities, expand on them, and have the organizational depth to undertake more ambitious activities. In the next section we compare an ENTNEA institution with existing precedents and other proposed regimes.

\subsection{A Comparison with Precedents and Other Proposed Regimes}

In the following discussion, we will compare the conceptual ENTNEA institution to ASIATOM or PACATOM concepts. All three concepts concern regional cooperation in the peaceful uses of nuclear energy. However, the ENTNEA concept for enhancing nuclear transparency for confidence building differs from ASIATOM or PACATOM. ENTNEA would emphasize information sharing in place of the regulatory or management activities that are included in the ASIATOM or PACATOM concepts.

ENTNEA could pursue harmonious resolution of the issues arising among regional states operating nuclear plants and fuel cycle facilities. Via information sharing, regional states could increase mutual understanding, build multilateral confidence, and resolve issues arising from nuclear activities. Major characteristics of the ENTNEA concept would be as follows:

- Cost-effective administration: One organization could administer the various informal activities noted in the previous section more efficiently than separate processes.

- Regional information sharing in the fuel cycle: Transparency in reprocessing and separated plutonium storage could improve confidence in nonproliferation regimes. Information about technical measures in spent fuel and waste storage could bring cost and safety benefits.

- Analysis on selected topics as authorized by the parties: For example, staff could make periodic projections of material accumulations and the needs for fuel cycle facilities, or they could analyze safety issues.

- Organization of collaborative research on solving difficult problems like spent fuel and waste disposition in Northeast Asia.

To make the comparison clear, we will summarize existing cooperative regimes and contrast the ASIATOM/PACATOM concepts.

Some multilateral cooperative regimes related to the peaceful uses of nuclear energy are currently in operation. Such regimes are ABACC, EURATOM, and the IAEA. ABACC (Brazilian-Argentine Agency for Accounting and Control of Nuclear Materials) may possess some interesting features; therefore, we will discuss it in the next section as we consider organizational options for ENTNEA. 
EURATOM, which was established by treaty in 1956, includes both nuclear weapons states (the United Kingdom and France) and non-nuclear weapon states. Formed at the dawn of the peaceful nuclear age, EURATOM promotes uses of nuclear energy and provides an assured source of nuclear fuel to its member states. Since all EURATOM states are NPT signatories, EURATOM performs safeguards activities in cooperation with the IAEA. EURATOM cannot be a direct model, but many things can be learned from its experiences and applied to regional cooperation in Northeast Asia.(32) The regional management of nuclear fuel cycle facilities may be attractive for its cost-effectiveness. However, competition for exports and technical leadership may present problems in initiating such an institution in a region with established national industries such as Northeast Asia.

In 1996, the Council on Nuclear Energy and Disarmament in Tokyo first proposed the basic concept of ASIATOM. The main purpose of ASIATOM would be to contribute to the expansion of the peaceful uses of nuclear energy to meet increasing needs for electricity. ASIATOM would also ensure that all nuclear energy activities in the region would be carried out in a manner compatible with internationally agreed nonproliferation requirements. Within the framework of ASIATOM, regional centers for nuclear safety, plant operation, and for nuclear fuel cycle services (including waste storage/management, reprocessing, enrichment and regional safeguards/inspection systems) would be created.(33)

In 1997, Robert Manning proposed PACATOM as a nuclear cooperation regime. PACATOM's functions were stated initially as (1) to serve as a regional safeguards regime; (2) to strengthen physical protection and safety of nuclear materials; (3) to cooperate in monitoring radiation levels; (4) to improve safeguards standards and practices; (5) to cooperate on the storage and management of spent fuel; (6) to establish a regional plutonium bank; and (7) to dispose of fissile materials from dismantled weapons.(34)

Continuing discussions of PACATOM under the auspices of the Council for Security Cooperation in the Asia Pacific (CSCAP) have emphasized the benefits of cooperation in the back end of the fuel cycle and reduced the emphasis on assuming safeguards responsibilities. The CSCAP discussions have also underlined the need for a step-by-step development of cooperation, consistent with ideas in the preceding section of this report (Section 3.2).

Some proponents of ASIATOM and PACATOM focus on regional management of facilities and nuclear safeguards. These forms of ASIATOM or PACATOM would require a comprehensive monitoring regime and an organization for nuclear cooperation, which might be equivalent to another EURATOM.

From a South Korean perspective it is important that North Korea eventually would become a party to ENTNEA. North Korea will receive two LWRs from KEDO and has developed substantial technical skill throughout the nuclear fuel cycle. Such capabilities should be brought into the international order, even if it means structuring institutions with that goal in mind. We believe that North Korean participation is more likely if ENTNEA emphasizes information sharing rather than regulation, safeguards, or facility management.

Having contrasted ENTNEA with other approaches to regional cooperation, in the next sections we will explore some organizational aspects of the concept. The South American precedent, ABACC, may be helpful when we consider institutional possibilities for ENTNEA.

\subsection{Methods and Support for Informal Transparency Activities}

Implementing informal transparency activities in the near term, while building a foundation for an eventual institution, will require enabling agreements and financial support. Analysis of the opportunities can be categorized according to various criteria depending upon the requirements of the parties.

First, we should make a distinction based on the number of parties. In Northeast Asia and in consideration of the issues noted in Section 2, there are several two-sided and three-sided issues, such as decommissioning submarines in Russia and storing low-level waste in North Korea. Therefore, bilateral and trilateral approaches may be very effective even if they are not particularly grand in concept.

Second, we might consider the authority level at which information sharing might occur, that is, who would organize the procedure and receive the data. The level should be about equal to the sensitivity of the data; interactions at too low a level might amount to a breach of security and at too high a level could be inefficient. Sharing safety information can illustrate this: For demonstrating safe emissions, public channels and organizations such as citizen groups or academic panels could be effective. On the other hand, for organizing emergency response in the case of a radiological emergency, the data should be confined to emergency response authorities in order to avoid a public panic.

Existing organizations offer great efficiency through established working relationships. A discussion of activities in an ENTNEA concept does not suggest that existing organizations have failed in their mission in some way. Rather, this discussion may generate regional support for expanded roles of certain organizations. For example, data sharing in support of the Convention on Early Notification of a Nuclear Accident might be organized under the auspices of the WANO or as part of an IAEA regional technical assistance project.

Third, budgetary requirements are another way to categorize organizational needs. At the low end are activities like sharing radiation monitoring reports for the purpose of refining transport models; the data is already available, so costs would be very low. Real-time transparency in wide-area radiation monitoring could be more expensive because of the communications costs. Larger expenses would be encountered if parties decide to standardize their systems and perform cross-calibration tests.

Enhanced transparency in nuclear material storage would involve higher expenses for monitoring technology, personnel, and communication. At each facility some sensors and cameras, a control system, and a data acquisition computer would be required. Installation labor, maintenance, and communications would involve substantial expenses outside of the existing budgets. 
None of these are large expenses compared to the facility costs; however, the Northeast Asian financial crisis requires careful justification of new projects.

\subsection{Institutional Possibilities for ENTNEA}

The foregoing discussion considered near-term activities in enhanced nuclear transparency of an informal nature. Now we might consider the form of an institution for nuclear transparency that might grow out of successful regional cooperation activities. The nature of the institution presented here is speculative, not intended to be prescriptive, and not an inevitable conclusion to a process.

Let us consider the requirements of an institution that might have responsibility to:

- share information on the regional nuclear fuel cycle activities

- analyze selected topics as authorized by the parties

- organize collaborative research on solving common problems

An institutional model might be taken from the Argentina-Brazil agreement (ABACC). $(35)$ Of course, the ABACC organization only covers the facilities of two countries, which in total are about comparable to Taiwan or South Korea, but it does have safeguards responsibilities in collaboration with the IAEA. ABACC might be a useful example because the organization is a purely South American invention to suit the bilateral needs of Argentina and Brazil. The charter of responsibilities of an ENTNEA institution would be different from that of ABACC, reflecting the information-sharing emphasis rather than safeguards.

ABACC has a central organization, permanently located in Rio de Janeiro. Although the Head and Deputy Head of its Secretariat rotate each year between the two parties, the location remains fixed because of the need for databases and a permanent professional staff. The permanent staff consists of about six technical and four administrative professionals, supported by a few office staff. With a total budget of only \$US $2.3 \mathrm{M}$, the organization depends upon the services of roughly 50 part-time experts from the two countries, who perform the technical work on temporary loan from their home institutions. These experts work for ABACC for brief periods (for example, for an inspection), and then return to their normal duties in laboratories or universities.

Although the nuclear industries of Northeast Asia are much larger than those of Argentina and Brazil, an institution focusing on information sharing and with no safeguards inspection responsibilities might be approximately of ABACC proportions. We belabor this point to avoid the tendency to assume that an ENTNEA should resemble EURATOM or the IAEA in size, scope, or budget.

In this kind of an institution the other ENTNEA responsibilities might fit easily. For analysis of selected topics, for example, projections of spent fuel accumulation and storage needs, an ENTNEA could commission a panel of distinguished experts from regional universities and laboratories. Using the ABACC model, the experts' salaries would be contributed by their home institutions.

Whether the informal ENTNEA activities would culminate in an institution would depend upon whether the institution satisfied pragmatic needs and was acceptable politically. Potential evolution of an ENTNEA institution into ASIATOM/PACATOM roles would also be determined in the future.

\subsection{Conclusions and Recommendations}

This paper addresses several issues related to nuclear development, including safety, environmental protection, and nonproliferation. The solutions suggested here center on sharing information to solve technical problems or lessen concerns about nuclear activities. We have suggested an ENTNEA concept that would be composed of near-term, informal activities and an eventual regional institution. The near-term activities would address specific concerns and build a tradition of cooperation. In the longer term, that tradition might evolve into an institution, which would combine these and other cooperative activities for the mutual benefit of regional parties.

We distinguish between the information-sharing focus of the ENTNEA concept and various precedents and alternative proposals that emphasize regional management and control of nuclear industries. Because all regional parties already have safeguards agreements with the IAEA, there may be no benefit in an ENTNEA institution taking over safeguards. Because the prospective parties already have substantial nuclear industrial expertise, there also may be little benefit from ENTNEA management or ownership of facilities. Thus, unlike a EURATOM, ASIATOM, or PACATOM concept, the ENTNEA concept addresses regional concerns through information sharing for enhanced transparency. This would not preclude an evolution of ENTNEA to serve managerial or accounting roles at later times.

Establishing a regional nuclear transparency institution like ENTNEA would depend upon a pre-existing tradition of nuclear cooperation. Our initial suggestions would help build this cooperative tradition through specific, non-institutionalized transparency activities, each of which relates to one or more specific nuclear concerns. Methodologies for these informal activities are described in detail in the appendix.

Activities that enhance the transparency of nuclear safety may be the most practical in the near term. All regional parties strongly endorse safety as a high concern. The following candidate transparency activities are available:

- Environmental radiation monitoring-Existing national systems could form the technical basis. Cooperation could help fill any gaps in coverage and standardize measurement and modeling. Information could flow in real time to improve emergency response capabilities or in periodic documents to advance modeling calculations.

- Support for existing safety conventions-Cooperation in prompt exchange of safety and emergency data could help implement safety conventions that many regional parties have already endorsed. New transparency measures might expand or supplement existing WANO and IAEA programs.

- Increased transparency in transportation safety-Technical cooperation could assist current activities to show the public that 
transportation is safe and help emergency response authorities protect the public in case of an accident.

Other transparency activities could include some more critical concerns. Progress might be slow, but discussion of these possibilities would be a transparency measure of some value in itself, as follows:

- Transparency at certain reactors-Issues of safety and nonproliferation might be addressed by increased transparency at nuclear reactors. We have noted a regional trend toward sharing some basic operational data to reassure the public that reactors are operating normally, and hence, probably with safety. A broader exchange of this data might strengthen regional public acceptance of nuclear energy, which may be useful for economic stability.

\begin{abstract}
Although IAEA safeguards are rigorously effective, regional parties might develop greater nonproliferation confidence through certain additional transparency measures. Between North and South Korea, the measures might encompass the KEDO light water reactors and the Ulsan heavy water reactors, for example.

- Transparency in spent fuel and separated plutonium-Problems with the back end of the fuel cycle are critical. Storage or disposal of spent fuel and separated plutonium introduce environmental and proliferation concerns that could be alleviated through information sharing. Cooperation might include solving technical issues associated with building repositories, monitoring the environment, or showing that nuclear material is secure. The latter would involve transparency supplemental to compliance with IAEA safeguards. Remote monitoring technologies might be especially helpful to avoid imposing additional operational costs upon the storage site operators.
\end{abstract}

In addition to near-term transparency measures, we have also outlined an ENTNEA institution that might evolve to perform useful roles in the long term. That institution could absorb the informal activities and add new responsibilities. These might include analysis of selected topics and organizing collaborative research on shared problems. In budget and management, the scope of the institution might be closer to the ABACC model than the EURATOM precedent.

The management and accounting roles that are included in the alternative institutional concepts, ASIATOM/PACATOM, might eventually be undertaken by a regional institution. Whether an ENTNEA might evolve in that direction would depend upon future events. We suggest that an information-sharing institution might be a necessary intermediate step before considering a regional management institution.

\title{
APPENDIX: Technological Approaches for Enhancing Regional Nuclear Transparency
}

\section{A.1 Potential Roles for Cooperative Monitoring}

Implementing agreements to share nuclear information may involve technically based cooperative monitoring.(36) Such monitoring can strengthen existing agreements and set the stage for continued progress, as is envisioned here in the ENTNEA concept. An agreement between two or more countries to increase nuclear transparency may bring about a temporary improvement in their relations, but more energy must be invested to make the improvement a lasting one. Investing time and resources in cooperatively monitoring a nuclear transparency agreement can contribute significantly to the permanence of the activity. Such an investment signals that the activity is important and that the countries are committed to its success. Cooperative monitoring also provides a method of documenting openly that nuclear activities are for peaceful purposes and are conducted safely. Finally, although an external party may assume partial responsibility for monitoring for nuclear transparency, full participation by the regional parties will strengthen the transparency activity.

Cooperative monitoring involves the collecting, analyzing, and sharing of information among parties to a transparency measure. Technologies incorporated into a cooperative nuclear transparency activity must be sharable among all parties, and all parties must receive equal access to the resultant data or information acquired in the system. A cooperative monitoring agreement should also include procedures for dealing with anomalous data and false positives. Such procedures are necessary for resolving problems constructively and are likely to involve human presence and activity.

In this appendix, we will consider many technological options for the nuclear transparency activities noted in Section 3 . We will concentrate on proven technologies that are widely available, some currently in use in the nuclear industry for internal control, protection, and regulation. Some of the techniques have been developed for IAEA safeguards and will be suggested here to provide transparency supplemental to safeguards. When combined with communication systems and data management capabilities, these technologies can provide powerful tools for implementing enhanced nuclear transparency measures.

In this appendix, we follow and expand upon an analysis methodology formulated by Richard Lincoln.(37) For each of the suggested enhanced nuclear transparency activities we will pose the following questions and note some considerations:

- What information would be relevant to the goals of the activity? Some information may be relevant but too sensitive to be shared.

- How might this information be shared? Methodological options can affect the usefulness of the activity.

- Who might provide or receive the information? Some data may be suited for wide dissemination while other data may need confidential treatment. 
- What are the costs and benefits of the activity? We should not overlook manpower costs in addition to actual technology costs. Also, benefits may result from direct information as well as general confidence building.

\section{A.2 Environmental Radiation Monitoring}

\section{A.2.1 What Information Could Be Shared?}

Three general types of airborne radionuclide concentration information exist within the Northeast Asia (NEA) region. A variety of governmental and industrial organizations presently gather (1) specific nuclear facility stack airborne count rate, (2) near-facility airborne count rate, and (3) facility-independent, or regional, airborne count rate. Most of the airborne radionuclide measurements focus on the total gamma (high energy $\mathrm{x}$ ray) count rate and do not include information about the energy distribution. This information can alert one that something out of the ordinary is occurring (the total count rate is higher than usual), but this information cannot identify what radionuclides (radioactive isotopes) are contributing to the higher total count rate. Some of the regional airborne concentration measurements characterize the gamma ray energy distribution as well as the total count rate of airborne particulate sources. This energy distribution information can be analyzed to identify what specific radionuclides are contributing to the observed total count rate. Some waterborne radionuclide concentration information is also gathered.

One initial informal experimental activity would utilize existing airborne radionuclide information from within the ROK and Japan and supplement this information with a few new total gamma count rate measurement stations in NEA areas outside of the ROK and Japan. These new measurement stations would be located in NEA countries that desire to join the environmental radiation information-sharing experiment. The NEWNET type of monitoring station is a good example of the technology. (See Figure A-1.)

Developed by Los Alamos National Laboratory, the NEWNET system monitors gamma rays from airborne radionuclides with 16 stations around the laboratory and in the surrounding communities. Each station combines radiation data with local wind speed and direction, and possibly other meteorological quantities. The entire station is solar-powered and a small radio transmitter sends the data every four hours. Thus, the station can be placed anywhere, without concerns about availability of electricity and telephone lines. Unique to this system is the idea of making the data available on the Internet for easy public access.

\section{A.2.2 How Could That Information Be Shared?}

The environmental radiation information can be used by emergency response personnel within the region as a warning of radiological emergencies. This "emergency response" use places a high value on data timeliness. Automated electronic transfer of this information is needed to support this level of data timeliness. A higher level of data confidence based on a data review or inspection process is less important than timely availability for the purpose of emergency response support. One conceptual approach is to have both the currently existing and the new measurement stations automatically electronically transfer the information to a common database that is available to all emergency responders within the region. Database software could be used to provide "alarms" when count rates increase rapidly.

The environmental radiation information can also be used to build confidence within the general public and the public decision-makers that nuclear facilities have not released significant amounts of radionuclides to the environment. Data review by some process that results in a time delay of a few hours or one day before release of this information is appropriate for at least the initial informalexperiment to prevent situations such as "lightning strikes on sensors" from reducing public trust in the system. The common database used for information transfer to regional emergency responders could be used as the basis for data review before release of the information to the public.

\section{Figure A-1. A Solar-Powered, Gamma-Ray Measurement Station near Los Alamos National Laboratory.}

\section{A.2.3 Who Could Share That Information?}

In the case of the ROK, the KINS currently collects data from the country-wide environmental radiation network and has plans to release the information to the public via the Internet. Some Japanese utility companies currently post near-site radiation data on a monthly basis on their web sites. These examples suggest that environmental radiation data might be made available to the general public in the future.

\section{A.2.4 What Are the Costs and Benefits?}

As much as possible, the system would incorporate existing radiation monitoring networks to minimize the additional costs of sharing information. The new costs arising from sharing this information include the communication system, database design, maintenance costs and the costs to establish any new measurement stations. The indirect costs of sharing this information include some potential for the loss of control of information that could be embarrassing or could involve liability in the case of a large-scale radioactive release. This indirect cost would be offset by the potential direct benefits of a more rapid emergency response to such a release and the associated public health, safety, and economic benefits of that more rapid response. Rapid identification of the area of concern for a radiological release has major benefits for the emergency responders, the public, and the agricultural industry of the region. Potential indirect benefits include increased trust by the public and other countries, as well as providing an early indication that a release did not come from a nearby regional facility.

\section{A.3 Spent Fuel and Separated Plutonium Storage}

\section{A.3.1 What Information Could Be Shared?}

Enhancing transparency in spent fuel and separated plutonium storage could involve sharing information to show (1) that nuclear 
material is not being moved out of the storage location without appropriate justification, and (2) that the amount of plutonium stored is consistent with the amount separated and the amount used. Event-triggered video coverage of storage or access areas could be used to share information to show when nuclear material is being moved out of the storage location. This information, combined with information about why and to where the material is being moved, could increase confidence that the nuclear materials are being moved and used for appropriate civilian applications. Material balance information (reactor irradiation history, separation, storage, and recycling usage) could be used to increase confidence that the amount stored is consistent with appropriate civilian applications. Material assay information that is consistent with the material balance information and appropriate civilian applications would also contribute to increased confidence.

\section{A.3.2 How Could That Information Be Shared?}

Event-triggered video coverage of storage areas could be shared using remote monitoring techniques developed within the International Remote Monitoring Project (IRMP). In the IRMP, motion, entry, or radiation sensors are used to trigger video camera images. (See Figure A-2.) The resulting images can be transmitted using telephone lines (appropriate for low numbers of image examinations) or satellite communication links (appropriate for more frequent image examinations or to support moving images, if desired).

\section{Figure A-2. Remote Monitoring of Spent Fuel Storage in Australia.}

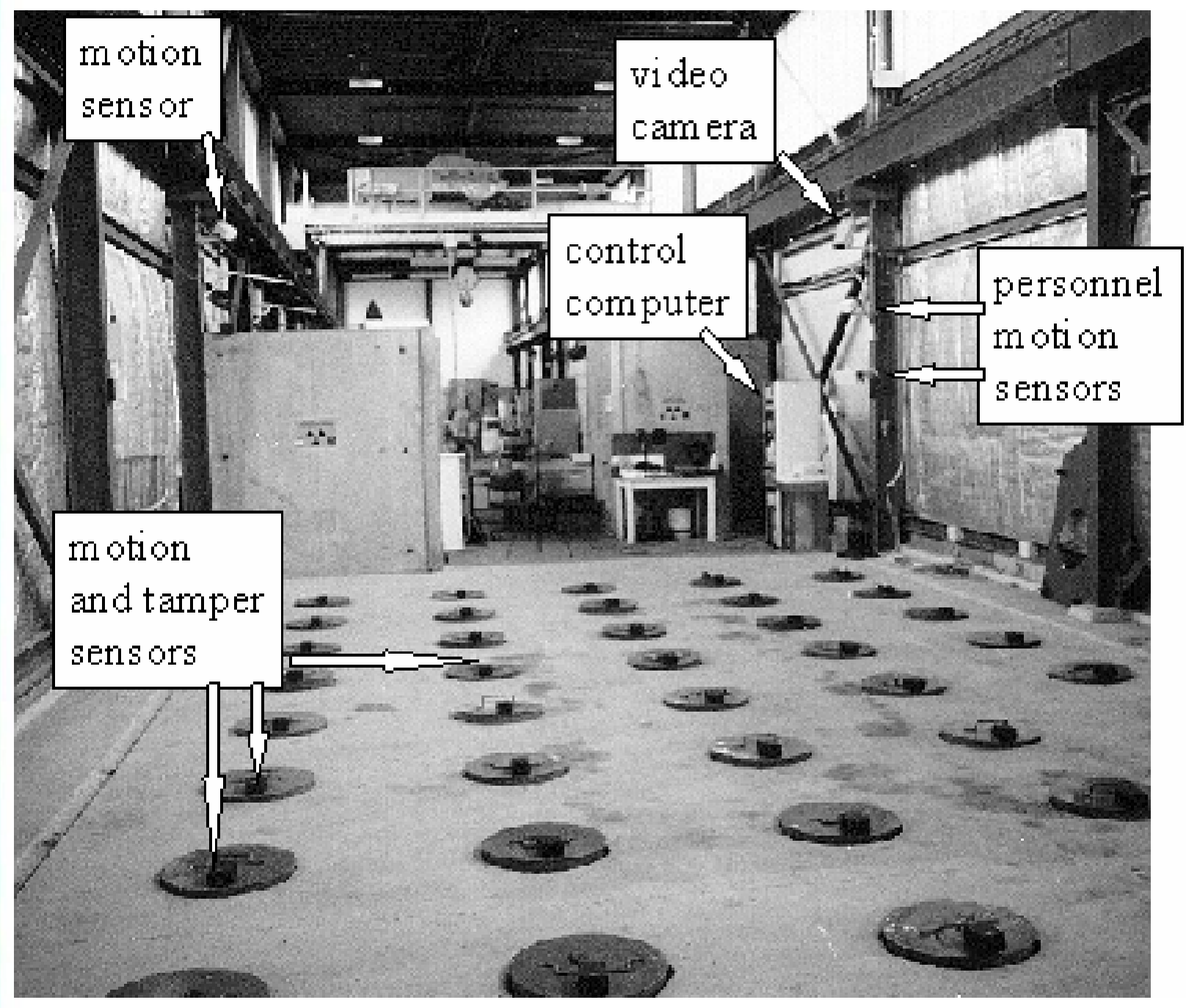

The spent fuel resides in casks sunk into the floor. On top of each cask are a motion detector and an electronic fiber seal to detect opening. Video cameras on the wall record images when signaled by the sensors that an event is happening.

Information about why and to where the material is being moved could be shared through discussions and the exchange of documents about fuel cycle material management plans. Material balance information could be included in the above discussions and document exchanges. Before reprocessing, the spent fuel assemblies are discrete, numbered items; documentation can show a consistent chain of custody. In the case of separated plutonium, which is a bulk material, the need for transparency is somewhat higher. Consistency between the need for fuel for power production reactors, the plans for plutonium separation, and the fabrication of mixed oxide (MOX) fuel could increase confidence that the movements of plutonium are for civilian applications.

Material assay measurements determine the isotopic content of the spent fuel and separated plutonium. In normal operation, light water reactors create plutonium with about $24 \%$ of the ${ }^{240} \mathrm{Pu}$ isotope. Lower abundance of this isotope could indicate the intent to accumulate material that would be more desirable for proliferation. Assay information could be shared by experts from organizations 
like the Korea Atomic Energy Research Institute (KAERI), who could participate in periodic cooperative measurements of the isotopic composition of samples of stored plutonium. At a somewhat lower level of transparency, isotopic composition information could be extracted from shared documentation that describes the isotopic composition of all materials in the storage.

\section{A.3.3 Who Could Share That Information?}

Japan is currently the only NEA country with significant storage of civilian fuel cycle plutonium. The ROK, Democratic People's Republic of Korea (DPRK), and China are regional countries with an interest in transparency of the Japanese plutonium stock. Some of the information is of general interest, like the total inventory, and has been made available publicly. Other data, like the isotopic content of the plutonium stocks, are technical and might be confined to research or regulatory agencies. Still other data, like movement plans, are sensitive and might only be shared with emergency response authorities under terms of confidentiality.

Reciprocity in sharing information could be attained by including similar information for spent fuel storage sites throughout the region. Again, because of the technical nature of the data, isotopic compositions could be shared between technical organizations, while total tonnage could be revealed to the public.

\section{A.3.4 What Are the Costs and Benefits?}

The direct costs of sharing this information include the staff time and travel costs for the visits and discussions, the documentation preparation or review time, and the staff time for analysis. The discussion and visit activities provide some level of confidence through consistency of multiple information sources.

The event-triggered video coverage of nuclear material storage involves some equipment (motion sensors, video cameras, and communication links) cost and some staff time for installation and maintenance of the hardware and software. The operating costs are primarily communication expenses and staff time to review the video images. An important objective of the initial experiments would be to evaluate the triggering rate to help estimate the long-term operating costs. The primary benefit of the triggered video coverage is a high level of confidence that no spent fuel or separated plutonium is being used for inappropriate applications.

\section{A.4 Nuclear Reactors}

\section{A.4.1 What Information Could Be Shared?}

Cooperatively sharing nuclear material accounting and protection information between countries could build confidence between those countries that nuclear materials associated with the nuclear power plants were being appropriately utilized and protected from theft or sabotage. This information sharing between countries should be considered as transparency above and beyond safeguards; it is designed to build confidence between the countries and is not intended to meet the information needs of any agreement between a country and the IAEA. Using nuclear transparency for confidence building between countries does not imply that IAEA safeguards are inadequate in any way.

One potential informalactivity involves sharing reactor fuel usage information such as reactor operating power history, refueling schedules, and fuel burn-up calculations. Another potential cooperation involves sharing reactor fuel protection information in the form of event-triggered video coverage of the reactor and fuel storage areas.

Information to build public confidence in safety could be shared. While safety cannot be proven, demonstration that basic parameters like temperature, pressure, and output power are within normal ranges can be helpful. Each reactor has many channels of this type of data continuously monitored and electronically available. In fact, in Japan several channels of basic parameters go in real time to the local city hall or environmental center for display to the local public.

In the following, we use the KEDO reactors to be built in North Korea as an example of enhanced transparency between South and North Korea. We emphasize the nonproliferation aspects.

\section{A.4.2 How Could That Information Be Shared?}

Operating power history could be shared with real-time remote monitoring. The KEDO LWRs are of the Korean standard design, which means that the control system is configured to allow about 200 data channels to be shared with the national regulator. Only a small portion of these need be shared between the two Koreas for a significant enhancement of transparency. The data transfer could be automatic by periodic telephone or by e-mail transfer.

Refueling schedules and fuel burn-up calculations could be shared with a combination of discussions, document exchanges, and visits. Reactor fuel protection information could be shared with event-triggered video images transmitted by satellite (appropriate when many images are transferred) or telephone lines (appropriate when a few images are transferred).

\section{A.4.3 Who Could Share That Information?}

The DPRK could offer event-triggered images of the KEDO LWR. In exchange, the ROK could offer event-triggered images of the ROK reactors of greatest interest to the DPRK; they may be interested in the CANDU (Canadian Pressurized Heavy Water Reactor) reactors at Ulsan. To broaden the cooperation, Japan could offer event-triggered images of a reactor or the separated plutonium storage areas. Organizations that could be involved include KEDO, KAERI, and KEPCO in the ROK, and the Japan Nuclear Cycle Development Institute (JNC), which is the successor to the PNC (Power Reactor and Nuclear Fuel Development Corporation).

\section{A.4.4 What Are the Costs and Benefits?}


The benefit of sharing reactor operating power history, refueling schedules, and fuel burn-up calculations is enhanced confidence that the reactor fuel is being used exclusively to generate electricity. The cost of sharing this information is primarily staff time to prepare documents for refueling schedules and fuel burn-up calculations. No additional cost, except for communications, would be incurred in sharing some of the standard operating data, because that is a built-in capability in the Korean Standard reactor.

Sharing event-triggered video images of the reactor and fuel storage areas builds confidence in nonproliferation, but it does so differently than by sharing burn-up calculations. That is, information is available in a more timely manner but in less detail. The costs of sharing event-triggered video images are primarily the costs of the equipment (motion sensors, video cameras, image storage hardware, and communication equipment) and the costs for satellite or telephone communication. Moreover, there would need to be staff time for maintenance of the system and for reviewing the images.

\section{A.5 Nuclear Safety Conventions}

\section{A.5.1 What Information Could Be Shared?}

Nuclear safety conventions $(38)$ that are under the auspices of the IAEA include the following:

- Convention on Early Notification of a Nuclear Accident

- Convention on Assistance in the Case of a Nuclear Accident or Radiological Emergency

- Convention on Physical Protection of Nuclear Material

- Convention on Nuclear Safety

- Joint Convention on the Safety of Spent Fuel Management and on the Safety of Radioactive Waste Management.

Of these five conventions, all but the last have presently entered into force.

Table A-1 indicates that the Convention on Early Notification of a Nuclear Accident has full Northeast Asian participation. This convention(39) establishes a notification system for nuclear accidents that have the potential for international transboundary release. Such releases could be of radiological significance for another state. It requires states to report the accident time, location, radiation releases, and other data essential for assessing the situation. Notification is to be made to affected states directly or through the IAEA, and to the IAEA itself. All of the above countries, including the DPRK, have identified a contact point (40) for the purposes of this convention.

\section{Table A-1. Year of Entry into Force for Northeast Asian States in the IAEA Safety Conventions}

\begin{tabular}{|l|c|c|c|c|c|c|}
\hline \multicolumn{1}{|c|}{ Convention } & China & DPRK & Japan & ROK & Russia & US \\
\hline $\begin{array}{l}\text { Convention on Early Notification of a } \\
\text { Nuclear Accident }\end{array}$ & 1987 & 1986 & 1987 & 1990 & 1986 & 1988 \\
\hline $\begin{array}{l}\text { Convention on Assistance in the Case of } \\
\text { a Nuclear Accident or Radiological } \\
\text { Emergency }\end{array}$ & 1987 & 1986 & 1987 & 1990 & 1986 & 1988 \\
\hline $\begin{array}{l}\text { Convention on Physical Protection of } \\
\text { Nuclear Material }\end{array}$ & 1989 & NA* & 1988 & 1982 & 1983 & 1982 \\
\hline Convention on Nuclear Safety & 1986 & NA* & 1995 & 1995 & 1996 & 1994 \\
\hline
\end{tabular}

* "NA" indicates that the country has taken No Action relative to the Convention.

The World Association of Nuclear Operators(41) (WANO) represents another form of international nuclear safety cooperative arrangement. The exchange of operating experience information is the basis of WANO's various programs. Information and event reports are submitted by each operating organization to its regional center, where they are reviewed for clarity and completeness and then distributed to all WANO members using an international electronic information exchange system. WANO also facilitates exchange visits, workshops, seminars, and peer review programs.

One potential informalexperimental activity would utilize shared environmental radiation information and would automatically transmit an electronic alarm to pre-selected emergency evaluation and response representatives. This same information could be transmitted to regional neighbors in a format compatible with the requirements of the Convention on Early Notification of a Nuclear Accident.

Another potential informalexperimental activity would share with other WANO sites operating data on a specific power reactor component that poses an operational problem (e.g., a motor temperature or backup system availability). This could help operators solve some technical problems in a cooperative mode.

\section{A.5.2 How Could That Information Be Shared?}


Automated alarms require timely transmittal and could be best implemented with automatic electronic transmission over satellite links or telephone lines. Selected individuals could even use commercial pagers as alarms. The timeliness needed for transmission of reactor component operating data depends on the nature of the specific study. Automatic electronic transmission may or may not be appropriate. E-mail may be timely enough for some cases, particularly for working on an engineering problem.

\section{A.5.3 Who Could Share That Information?}

Alarms associated with the Convention on Early Notification of a Nuclear Accident would involve sharing information between the regional environmental radiation monitoring stations and the regional emergency response authorities. This type of data would probably not be appropriate for direct public release.

Sharing of operating data on a specific power reactor component would occur between responsible component engineers (user, manufacturer, vendor, regulator, and other users).

\section{A.5.4 What Are the Costs and Benefits?}

The direct cost of sharing the Convention on Early Notification of a Nuclear Accident information is primarily that of the communication link. Indirect costs of sharing this information depend on the timeliness and effectiveness of the data evaluation before sending an electronic alert to State parties and the IAEA. There is a trade-off between the need for timely notifications and the need to avoid false alarms. The direct benefits of sharing the Convention on Early Notification of a Nuclear Accident information are primarily in rapidly identifying and focusing the area of concern for a radiological release. This rapid identification has major safety benefits for the emergency responders and the public. Potential indirect benefits include increased trust by the public and other countries.

The direct cost of sharing the WANO operational experience information might involve costs for special sensors (e.g., motor temperature) and communication equipment. The benefits of sharing the operational information include more rapid resolution of the operational issue and the furthering of regional trust and cooperation.

\section{A.6 Nuclear Material Transportation Safety}

\section{A.6.1 What Information Could Be Shared?}

Enhancing transparency in nuclear material transportation could include sharing information about the nuclear materials, the transportation packaging, physical protection arrangements, and the transportation routes. All of this information could be shared by discussions or document exchanges before, during, or after the shipment. Overseas shipments of nuclear materials to and from Japan already include these processes. $(42)$

Some of this information and some additional information could be shared in near-real time during the shipment using remote monitoring techniques. The physical location of the shipment, the physical protection of the nuclear material (status of a package seal, a door switch, or a motion sensor), or safety factors (container temperature, radiation detector output, or status of a smoke detector) can all be shared in near-real time. This information sharing can be arranged for truck, train, ship, or airplane transport and the shared information can be monitored from a fixed location or from a mobile location.

Potential informal experiments could include both document and near-real-time remote monitoring information sharing for international and/or domestic shipments within the Northeast Asia region. The ROK currently has domestic truck shipments of fresh fuel. Japan has domestic truck transportation and dedicated nuclear transport ship transportation of low-level waste and spent fuel. Japan also has international shipments of spent fuel, separated plutonium, and high-level waste, which are transported by special nuclear material ships. Any of these nuclear material transportation operations, or other regional transportation operations, could be used for information-sharing experiments. The Japanese international shipments already use remote monitoring for some information elements (for example, Global Positioning System (GPS)-based location information).

\section{A.6.2 How Could That Information Be Shared?}

Discussions or the sharing of documents could be used before, during, or after the shipment to share nuclear material transportation plans, current status, or results.

Near-real-time sharing of the broad range of information described above involves automated electronic transfers of information through satellite links.

One such system, the Authenticated Tracking and Monitoring System (ATMS), (43) uses INMARSAT (International Maritime Satellite) links to pass authenticated and encrypted data from the transportation operation to authorized recipients. The nuclear materials transport is monitored for location and the status of the physical protection or safety sensors. The data recipients can be anywhere in the world.

\section{A.6.3 Who Could Share That Information?}

Nuclear material transportation plans or near-real-time transportation information is of significant potential value to regional emergency response organizations (for example, fire, police, coast guard, or nuclear material protection organizations) that are expected to respond to a nuclear material transportation accident. Access to nuclear material transportation plans or near-real-time information would need to be controlled for shipments that involve a risk of sabotage. This access control could be implemented with password control and encryption software. In this case, regional emergency response organizations would be issued reception 
equipment and passwords to provide secure access to the shared information.

Less sensitive data, perhaps temperature and shipboard radiation levels, might be made available to the public on a daily basis to reduce safety concerns. Furthermore, the transporting agency could send this information without encryption to allow all interested parties to receive it.

\section{A.6.4 What Are the Costs and Benefits?}

The direct costs of sharing nuclear material transportation information by discussions or documents are the staff time and perhaps travel costs. The direct costs of sharing near-real-time information about nuclear material transportation operations include the cost of the sensors, support equipment, and communications.

Indirect costs of sharing nuclear material transportation information include the risk of providing information to terrorists or saboteurs (locations, material content, or protection arrangements). Data encryption can be used to control access to sensitive information. Information-sharing agreements would need to specify access limitations on some elements of the shared information.

The direct benefits of information sharing about nuclear material transportation operations include increasing the ability of emergency responders to minimize any potential public health and safety impacts associated with transportation accidents. Indirect benefits include reducing tensions and increasing trust between those responsible for the transportation operations and those exposed to potential risks.

\section{About the Authors}

Dr. Man-kwon Nam has been a Senior Research Fellow at the Korea Institute for Defense Analyses for ten years and now works as a chief of arms control studies. His major research area is arms control and verification, particularly security considerations regarding military negotiations between South and North Korea. He is currently participating in studies related to the Four Party Talks and inter-Korean package deals. He performed his Ph.D. research in industrial engineering at University of Illinois at Chicago, Illinois, USA.

Dr. Sung-tack Shin has been a Research Fellow at the Korea Institute for Defense Analyses for seven years and now works as a chief of special weapons studies. His major research area is non-proliferation on the Korean Peninsula, particularly nuclear control regimes. $\mathrm{He}$ is currently participating in studies related to North Korea's nuclear, missiles, and bio-chemical weapons issues. He performed his Ph.D. research in nuclear engineering at Rensselaer Polytechnic Institute in Troy, New York, USA.

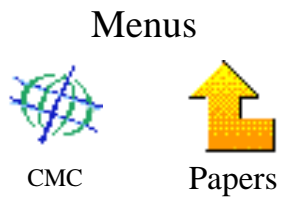

